RU Устойчивые словесные комплексы с компонентом Корf в современном немецком языке (к проблеме взаимосвязи лексики и фразеологии)

\author{
Гутарова А. В.
}

Аннотация. Целью данной работы является доказательство реальной связи лексики и фразеологии, формирования значения фразеологической единицы на основе значения ее компонентов и заложенности в значении компонентов значения всей фразеологической единицы. Научная новизна работы заключается в проведении исследования немецких устойчивых словесных комплексов с элементом Kopf с целью выявления взаимосвязи лексики и фразеологии. В результате доказывается семантическая соотнесенность фразеологических единиц с компонентом Корf с определенной семой взятого в прямом номинативном значении слова Корf и раскрывается перспективность проведения дальнейших исследований в данной области.

\title{
EN Stable Word Complexes with the Kopf Component in Modern German (on the Relationship between Lexis and Phraseology)
}

\author{
Gutarova A. V.
}

\begin{abstract}
The purpose of the paper is to prove the real connection between lexis and phraseology, the formation of the meaning of a phraseological unit based on the meaning of its components and the idea that the meaning of its components includes the meaning of the entire phraseological unit. Scientific novelty of the paper lies in studying German stable word complexes with the Kopf element in order to identify the relationship between lexis and phraseology. As a result, the researcher proves that there is a semantic correlation between phraseological units with the Kopf component and a certain seme of the word Kopf considered in the direct nominative meaning and sheds light on the potential for further research in this area.
\end{abstract}

\section{Введение}

Теоретическую базу данного исследования составили основополагающие работы по фразеологии (Ш. Балли, В. В. Виноградов и др.), подчеркивающие близость фразеологических единиц (далее - ФЕ) со словом. Тем самым ФЕ подводились под статус явлений языка, а не только речи, и таким образом имплицитно подразумевалось, что фразеологизмы имеют знаковый характер. В целом ряде работ тезис об известной эквивалентности ФЕ слову толковался несколько односторонне, что вызвало появление ряда исследований, показывающих, что фразеологизм семантически не адекватен слову (Архангельский, 1964; Чернышева, 1973; Гутарова, 2008).

Однако рассмотрение свойств ФЕ (как сочетание слов в первую очередь) проводится в определенном смысле односторонне, очень мало учитывается факт раздельнооформленности ФЕ, раздельнооформленность рассматривается, как правило, с точки зрения расширения возможностей употребления ФЕ в тексте (дистантность компонентов ФЕ, замена компонента синонимичным словом, контаминация и т.п.). До сих пор не выяснено, что дает фразеологизму форму словесного комплекса в семантическом отношении и почему столь совершенно организованный механизм, каковым является язык, прибегает особенно часто именно к словосочетанию и прочим видам сочетания слов для передачи эмоционально-оценочного содержания мысли, что нового вносит усложнение архитектонической структуры ФЕ в значении ФЕ по сравнению со значением слова.

Ответить на вопросы можно, лишь учитывая статус фразеологии в иерархии уровней языковой структуры. Мы исходим из того, что фразеология занимает промежуточное положение между уровнем слов (чисто языковым уровнем) и уровнем свободных словосочетаний (уровнем, выходящим за рамки языка и относящимся к речи) (Гутарова, 2008; Маслова, Гутарова, 2011). 
Формальную структуру ФЕ образуют слова, функционально фразеологизм соотносим прежде всего со словосочетанием.

Семантика свободного словосочетания еще мало исследована. Однако уже определение словосочетания, данное А. М. Пешковским в 1914 году, подчеркивает очень важную сторону словосочетания: объединение слов «в речи и в мысли» (Пешковский, 1956). Отсюда делается еще более важный вывод, что значение словосочетания, как правило, нельзя свести к простой сумме значений входящих в него слов.

Следует подчеркнуть еще одну особенность свободного словосочетания, отмечавшуюся отечественными синтаксистами, теоретически обоснованную с позиций порождающего синтаксиса и порождающей семантики. Речь идет о «коррелятивной близости предложения и словосочетания» (Никитевич, 1985). В данной работе особый интерес представляет прежде всего характер номинации в предложении и в свободном словосочетании - в обоих случаях мы сталкиваемся с ориентированностью на ситуацию, в том смысле, как существительное ориентировано на предмет, прилагательное - на признак и т.д.

Фразеологизм, генетически восходящий в конечном итоге к свободному словосочетанию, не может не отразить перечисленных основных черт свободного словосочетания. Ситуативная направленность номинации ФЕ в период ее возникновения и становления оказывает решающее влияние на формирование значения фразеологизма.

Актуальность данной работы заключается в изучении семантической соотнесенности ФЕ с компонентом Kopf с определенной семой взятого в прямом номинативном значении слова Корf. Основным методом изучения является компонентный анализ, введение которого в практику лингвистического исследования позволяет проследить семантические процессы, происходящие в свободном словосочетании.

Задачами данной работы являются изучение развития семантических линий в значении компонента фразеологической единицы при формировании ее значения, выявление реальной связи лексики и фразеологии на примере устойчивых словесных комплексов немецкого языка с элементом Kopf, представление семантической соотнесенности ФЕ с компонентом Корf с определенной семой взятого в прямом номинативном значении слова Корf.

Практическая значимость работы: материалы исследования могут быть использованы в вузах гуманитарного направления при изучении спецкурсов и спецсеминаров по теоретическому, практическому, сравнительному языкознанию. Полученные данные могут найти применение в процессе учебно-методической деятельности при создании учебников, учебных пособий.

Материалом исследования являются устойчивые словесные комплексы (далее - УСК) немецкого языка с элементом Kopf (голова) на примерах, взятых из специальных толковых и фразеологических немецко-русских словарей, лингвистических энциклопедий и др. (Бинович, 1995; Лепинг, 2017; Lötzsch, 1884; Paul, 2007 и др.). Перевод с немецкого на русский язык всех примеров и терминов дается автором работы.

\section{Основная часть}

Ситуативная ориентированность фразеологизма в момент его становления открывает языку дополнительные возможности: за счет оригинального набора элементарных смыслов, которые, как известно, в чистом виде в языке не встречаются, создавать новые смысловые единицы, отмеченные в национально-экспрессивном отношении. Все это не мешает такому словосочетанию перейти со временем в разряд единиц языка, где цельность номинации довлеет над структурной раздельностью (Гутарова, 2008).

Фразеологизм состоит из слов, хорошо вычленяющихся во фразеологизме даже при всей его «цельности номинации» и, как правило, хорошо знакомых носителям языка. В ФЕ, как бы сильно не были десемантизированы компоненты, никогда не достигается та степень опрощения, которая отмечается в слове, утратившем внутреннюю форму. У ФЕ всегда, за исключением небольшого числа некротизмов, жива внутренняя форма, допускающая разные толкования и контекстные употребления ФЕ. Все это, а также сама форма фразеологизма (сочетание слов) позволяет интерпретацию ФЕ.

Именно благодаря возможности, а подчас и необходимости интерпретации ФЕ, возникает явление, получившее в литературе по фразеологии название широкого значения фразеологизма (Чернышева, 1973; Мордвилко, 1964).

Значение фразеологизма осложняется тем, что отношение к денотату ситуативно зашифровано, как бы преломлено через призму ситуации, хотя не всегда реально возможной, но всегда логико-ассоциативно соотносимой с определенным денотатом. Эффект фразеологизма заключается в его двунаправленности: соотнесенности слова-компонента с его прямым номинативным значением во всей глобальности и определенным оттенком значения, актуализируемым благодаря форме ФЕ-словосочетания за счет его внутреннего контекста и вычленяемым вследствие логико-ассоциативной корреляции ФЕ, вернее, зашифрованной в ней ситуации, и денотата.

Наличие такой логико-ассоциативной схемы внутренней формы ФЕ объясняет и многочисленные случаи вариативности ФЕ типа: einen Vogel im Kopfe haben (быть не в своем уме), Tauben im Kopfe haben (быть с причудами, со странностями) и случаи речевой модификации ФЕ, носящие окказиональный характер.

Здесь важно проследить логико-ассоциативные связи значений компонентов ФЕ и значений фразеологизмов с этими компонентами. В данной работе анализу подвергаются устойчивые словесные комплексы немецкого языка с элементом Kopf (голова).

Исследователей фразеологии заинтересовал тот факт, что далеко не каждое слово входит во фразеологический словник и что «фразеологический состав соотносится со своим собственным инвентарем весьма 
неравномерно» (Мордвилко, 1964; Чернышева, 1973). Многие немецкие ФЕ концентрируются вокруг немногих слов. В качестве наиболее продуктивных в сфере фразеологии называют в первую очередь слова, обозначающие части тела человека или животного.

Выбор слова Kopf в качестве маркера в данной работе продиктован не только большим количеством единиц, содержащих данный элемент, и высокой частотностью их употребления, но и их большим тематическим многообразием.

Прежде чем перейти к рассмотрению ФЕ с элементом Kopf, остановимся на истории самого слова Корf, что поможет понять дальнейшее развитие элементов значения данного слова. Словарь Г. Пауля дает следующую справку (Paul, 2011), из которой видно, что основное значение слова Корf развилось как метафорическое через значение «сосуд», «вместилище мозга». Известным основанием для сравнения послужила, видимо, форма головы. Можно предположить также, что ножка кубка ассоциируется с шеей, на которой как бы крепится голова - сосуд.

На наш взгляд, самым удачным является толкование слова Kopf в словаре Р. Клаппенбах: “...oberster als Sitz des Gehirns und Zentrum der Sinnesorgane, wichtigster Körperteil des Menschen, der Tiere” (самая верхняя точка как вместилище мозга и центр органов чувств, важнейшая часть тела человека, животных) (Klappenbach, 1994). На основе данной дефиниции выделены следующие семы: 1. Körperteil des Menschen (Tieres), 2. Oberster Körperteil, 3. Wichtigster Körperteil, 4. Sitz des Gehirns, 5. Zentrum der Sinnesorgane (1. Часть тела человека (животного), 2. Самая верхняя точка на теле, 3. Важнейшая часть тела, 4. Вместилище мозга, 5. Центр органов чувств).

Все собранные на основе специальных фразеологических и толковых словарей УСК с компонентом Корf проверяются на соотнесенность их значения с выделенными семами слова Корf. Принадлежность УсК к данной семе слова Кopf считается доказанной в следующих случаях:

1. Если в дефиниции ФЕ и семы слова Корf есть общие части. Так, например, УСК den Kopf in den Sand stecken (прятать голову в песок) трактуется в словарях: “sich gegenüber Gefahren blind stellen, Gefahren nicht sehen wollen” (оставаться слепым в опасности, не желать понимать опасность) (Brockhaus, 1984); “vor den Tatsachen die Augen verschließen” (перед фактами закрывать глаза) (Klappenbach, 1994). Принадлежность слов blind (слепой), sehen (видеть, смотреть), Augen (глаза) к тематическому ряду Sinnesorgane (органы чувств) не вызывает сомнений, и на этом основании можно сказать, что данный фразеологизм относится к семе Zentrum der Sinnesorgane (центр органов чувств).

2. Родство УСК и семы слова Корf считается доказанным, если общие или тематически родственные части определений могут быть получены через цепочку последовательных дефиниций. ФЕ die Köpfe zusammenstecken (шушукаться, шептаться, вести тайные переговоры) словарь Брокгауза Ф. расшифровывает как "miteinander tuscheln” (друг с другом шушукаться, шептаться), tuscheln трактуется как "heimlich (miteinander) flüstern” (тайно друг с другом шептаться, шушукаться), flüstern объясняется как "leise, ohne Stimme, ohne Tonreden" (говорить тихо, не в голос, беззвучно), leise объясняется “nur schwerhörbar; Ggs.: laut” (говорить еле слышно; ант.: громко) (Brockhaus, 1984).

Только последнее звено этой цепочки приводит нас к семе Zentrum der Sinnesorgane. Leise принадлежит к тематическому ряду Gehör (слух), то есть опять выходим на сему Sinnesorgane. Да и чисто житейские наблюдения подтверждают образ die Köpfe zusammenstecken: когда шушукаются, говорят о чем-то тайном, то шепчут на ухо.

3. В ряде случаев установить отнесенность значения УСК к определенной семе Корf можно чисто лингвистическим путем, учитывая сочетаемость лексем в немецком языке. Так, тематическое родство с определенной семой слова Kopf может считаться доказанным, если при подстановке вместо слова Корf другого слова получается словосочетание, синонимичное исходному. Слово-заменитель в этом случае и определяет соотнесенность исходного УСК с семой слова-компонента. Так, в выражениях etwas will nicht aus dem Kopf (что-то не запоминается); etwas im Kopfe behalten (запомнить что-то); was man nicht im Kopfe hat, muss man in den Beinen haben (русский эквивалент: дурная голова ногам покоя не дает) - на передний план выступает сема Sitz des Gehirns, т.к. синонимичными им являются соответственно: etwas will nicht aus dem Sinn (что-то не запоминается); etwas im Gedächtnis behalten (запомнить что-то); wer kein Gehirn hat, habe Beine (буквально: за безмозглость расплачиваются ноги).

4. Иногда родство (хотя бы тематическое) обнаруживается только при логико-смысловой дешифровке ФЕ.

Сколько бы не рассматривались толкования пословицы den Kopf halt kühl, die Füsse warm, das macht den besten Doktor arm (русский эквивалент: держи голову в холоде, живот в голоде, ноги в тепле), не найдутся никакие указания на интерпретацию слова Корf в данном выражении. Доказательство строится методом от противного. Совет держать на холоде органы чувств не вяжется с общим смыслом пословицы и поэтому отпадает сема Sitz der Sinnesorgane. Лишено какого бы то ни было смысла и отнесение данного УСК к семе wichtigster Körperteil, т.к. самую важную часть тела следовало бы особенно беречь, а не держать в холоде, как это советует пословица.

5. В особо сложных случаях используется многочисленный фразеологический материал, учитывая типичные для фразеологии (у которой своя логика и свои ассоциации) способы передачи одного и того же значения. Исходным пунктом рассуждений в таком случае будет не внутренняя форма УСК, а его значение. С помощью ономасиологии прослеживаются возможности, направления развития значения, ассоциации и логические приемы, используемые фразеологией для передачи данного содержания, что помогает понять внутренний стрежень формирования значения.

Так, например, в идиоме Butter auf dem Kopf haben (иметь рыльце в пушку) на первый взгляд трудно понять, почему именно Butter (масло) и почему именно auf dem Kopf (на голове), синтезируясь, дают значение 
«иметь рыльце в пушку», «иметь нечистую совесть». Значение «натворить что-либо», «иметь что-либо на совести» в немецкой картине мира предполагает, что если масло потечет сверху и «запятнает» всего человека, то «выдаст его с головой». Так что выражение Butter auf dem Kopf haben можно отнести к семе oberster Körperteil.

Проведенное исследование показывает, что все УСК с компонентом Корf соотносимы с какой-нибудь семой данного слова, взятого в прямом номинативном значении. Реализация сем слова Корf происходит в единицах с семантическим сдвигом в количественном отношении неравномерно. Самый «весомой» во фразеологии оказалась сема Sitz des Gehirns, а если объединить семы Sitz des Gehirns и Zentrum der Sinnesorgane как центр нервно-психической деятельности и добавить к ним УСК, относимые к семе wichtigster Körperteil, являющейся как бы следствием двух последних сем, то получается, что в большинстве анализируемых единиц компонент Kopf выступает на основе функционального признака как репрезентант сознания, центр нервнопсихической деятельности, важнейший орган жизнедеятельности человека.

Все это говорит о смещении центра семантической структуры слова Kopf во фразеологии в сторону дифференцирующих сем, а именно о функциональном крене семантики данного слова в составе УСК.

Рассмотрим далее линии развития компонентов значения слова Корf, взятого в прямом номинативном значении во фразеологии (при широком понимании термина «фразеология»). Семы компонента Корf посвоему интерпретируются в УСК. Не всегда сема слова Корf участвует в формировании значения УСК в «чистом» виде, чаще она аранжирует ФЕ благодаря семантическим трансформациям, которые, однако, носят регулярный характер, т.е. значения слов-компонентов УСК программируют его значения.

Перейдем непосредственно к рассмотрению развития значений УСК на базе определенных сем словакомпонента УСК.

Сема Körperteil реализуется во многих ФЕ, при этом не учитываются функции головы как особой части тела. Поэтому неслучайным оказывается тот факт, что в языке существует ряд параллельных фразеологических образований, где элемент Корf замещается наименованиями других частей тела. Наряду с выражением Корf an Kopf (ноздря в ноздрю, вплотную, голова к голове, вровень) существуют аналогичные Schulter an Schulter (плечом к плечу, дружно), Hand in Hand (рука об руку, дружно), обозначающие несколько иной вид построения, но фразеологическая идея та же. Параллельное существование выражений типа den Kopf (die Hände in den Schoß, die Flügel) sinkenlassen (опустить голову, повесить голову, пасть духом: опустить руки; пасть духом, опускать руки) обогащает язык, разнообразит речь, способствует тому, что подобные выражения не «приедаются», звучат свежо и ярко. В обороте j-m ein Loch in den Kopf (in den Bauch) reden (настойчиво уговаривать, уламывать кого-то) не ощущается противопоставления Корf (голова) и Bauch (живот), в то время как обычным для фразеологии является противопоставление значений этих слов по функциональному признаку. Слово Корf придает всему фразеологизму доступность, конкретность образа (Богуславская, 1997).

На основе компонента Körperteil возникли три большие группы ФЕ. Первую группу объединяет общее значение «эмоция», где эмоциональное состояние человека описывается через внешнее проявление этого состояния (Чернышева, 1973). Так, die Arme über den Kopf strecken (буквально: вытянуть, поднять руки над головой) - символ удивления, ужаса, отчаяния; sich am Kopf kratzen (чесать в затылке) - сомнение, смущение; den Kopf schütteln (качать головой) - несогласие, отказ; sich an den Kopf greifen (хвататься за голову: спохватиться) - удивление, отчуждение и т.д. Приходится иметь в виду не только теоретическую возможность соединения тех или иных языковых элементов, но и характер их реального бытования в конкретном языковом общении членов данного человеческого коллектива - так называемые реалии данной социолингвистической общности (Гутарова, 2008).

Зачастую настроение, душевное состояние человека передается через тонус, физическое состояние частей тела. Ослабленный тонус мышц служит символом физического недомогания, усталости, отсутствия душевного равновесия, слабоволия: den Kopf hängen (sinken) lassen (senken) (пасть духом, отчаяться, повесить, опустить голову). Гордо поднятая голова - символ самообладания, мужества, стойкости, достоинства: den Kopf hochhalten (aufrecht halten) (гордо держать голову), Kopf hoch! (выше голову, не падай духом, выше нос, не унывай, держись), den Kopf heben (поднять голову).

Вторая группа фразеологизмов с элементом Kopf, где данная единица реализуется в значении Körperteil, объединяется под общим названием «воздействие на объекта». Объектом в данном случае является третье лицо, воздействие, как правило, отрицательное (однако не исключается возможность положительного результата). Само действие может быть самым различным: физическим - Eis auf den Kopf bekommen (запариться, получить трудную задачу), моральным - j-n vor den Kopf stoßen (schlagen) (оскорбить, задеть), sich bei den Кӧрfen kriegen (сцепиться). В данных примерах значение порицания, оскорбления, унижения выводится из значения физического действия.

Третья группа УСК, возникших на базе сем Körperteil, объединяет единицы, где данная сема трансформируется в значение «человек».

В немецком языке в ряде контекстов Корf служит для репрезентации значения «человек». В примере fauler Kopf (лентяй) слово Корf выступает в значении «человек как носитель каких-либо качеств, способностей».

Слово Kopf со значением «конкретный человек», «конкретное лицо» абстрагируется «человек вообще», «единица общества, населения»: je Kopf (на душу населения), pro Kopf (на душу населения, на (одного) человека), auf den Kopf der Bevölkerung entfallen (приходиться на душу населения). Метонимический перенос «голова»«единица» (при счете) относится к самым древним пластам лексики. Неслучайно у целого ряда народов стадо скота исчисляется количеством голов скота.

В немецком языке оба слова Корf (голова), Mensch (человек) мужского рода, т.е. изменения грамматической категории ожидать не приходится, но смысловое удаление слова Корf в значении «часть тела» и в значении 
«человек» весьма ощутимо. Об этом свидетельствует очень значительная группа как устойчивых сочетаний слов, так и сложных слов: Dummkopf (глупец), Hitzkopf (горячая голова, вспыльчивый человек), Ноhlkopf (глупец, пустая голова, бестолочь) и т.д.

Второй выделенный нами компонент значения der oberste Körperteil - бросающийся в глаза признак. Поэтому так легко поддаются дешифровке Dach (башка), Oberstübchen (башка, черепушка, чердак), Deckel (башка) синонимы разговорной речи к слову Корf. Данная сема реализуется в относительно небольшом числе ФЕ, но развитие семантических линий этого компонента многообразно.

Голова диаметрально противопоставляется ногам, что особенно четко ощущается в выражении von Kopf bis Fuß (с головы до пят, с головы до ног, до мозга костей), что означает von oben bis unten (сверху донизу), далее это значение развилось в ganz und gar (полностью, целиком, всецело, до мозга костей), durch und durch (на все сто процентов, до мозга костей), völlig (полностью, совершенно). Следующей ступенью развития значения можно считать то, что рост человека стал восприниматься как своего рода мера высоты, где ноги - начальная, а голова - конечная точка отсчета. Корf становится элементом квантитативной характеристики, что ощущается в выражении bis über den Kopf in Schulden stecken (bis an den Hals in Schulden stecken) (сидеть по уши в долгах).

Высокий рост как символ некоторого физического превосходства трансформируется во фразеологии в превосходстве вообще, например, Er überragt sie um einen Kopf (Он на голову, на порядок выше нее). Имеется в виду любой вид превосходства (умственная, моральная и т.д.). В антонимичном обороте Er reicht ihm nicht an die Fersen (Он ему в подметки не годится) подчеркивается ущербность, ничтожество. Таким образом, элемент Корf становится элементом квалитативной характеристики.

Голова как конечная точка измерения может рассматриваться и как предел физических и прочих возможностей. Именно этот оттенок значения превалирует в выражении Es wächst mir über den Kopf (это выше моих сил, я не могу с этим справиться), в качестве переводного эквивалента можно использовать русское выражение «выше головы не прыгнешь». «Отголоски» данного значения обнаруживаются в обороте ӥber die Köpfe der Zuhörer hinwegreden (ohne verstanden zu werden) (быть непонятным для слушателей). В выражении sich über den Kopf einer Person hinweg an j-n wenden (обратиться к кому-либо (вышестоящему) через голову кого-либо (например, своего начальника) в основу легло значение пренебрежения к одному лицу и предпочтение другого лица. Сюда примешивается бытующая ассоциация: начальство - верх.

Сема wichtigster Körperteil является следствием важности функций, выполняемых самой головой. Голова центр психической деятельности человека и высших видов животных. Осознание важности головы в жизни человека красной нитью проходит через фольклор и фразеологию, например, Dein Reichtum ist dein Kopf (буквально: Твое богатство - это твой ум).

Развитие значений этой семы шло от конкретного к абстрактному. В выражениях den Kopf ins Loch stecken (дословно: положить голову в дыру, т.е. на плаху, den Kopf in die Schlinge stecken (лезть в петлю), den Kopf aus der Schlinge ziehen (избежать (смертельной) опасности, вытащить голову из петли) четко выступает сема Körperteil, в основе внутренней формы фразеологизмов ситуация казни.

Значение «самый важный» (Superlativ - превосходная степень) трансформируется в усиление, когда хотят подчеркнуть, что все ставится на карту. Например, как усилие, достигаемое при помощи языковых средств, звучит во многих ФЕ сочетание Kopf und Kragen (голова = жизнь) - es geht um Kopf und Kragen (речь идет о жизни и смерти), Kopf und Kragen kosten (рисковать головой, стоить головы), Kopf und Kragen verlieren (погибнуть), sich um Kopf und Kragen reden (поплатиться головой за свои слова, неосторожно высказаться), Kopf und Kragen aufs Spiel setzen (рисковать жизнью). Популярности данного сочетания способствует аллитерация.

При описании семы Sitz des Gehirns можно отметить целый ряд противопоставлений, где голова как мыслительный центр противопоставляется по функциональному признаку другим частям и органам тела, например, Was die Hand schreibt, dafür muss der Kopf halten (Думай, что делаешь; буквально: За то, что пишет рука, отвечает голова); Kopf und Ellenbogen zusammennehmen (шевелить мозгами изо всех сил) и др.

Не случайным является и тот факт, что слово Корf замещает в разговорной речи слова, например, сложные существительные Gedankengenerator, Gedankenkondensator, Gedankenscheune переводятся «голова, чердак», а сложные номинации Gehirnkasten, Hirnkasten, Verstandeskasten переводятся «башка, мозги, мозг, голова» и др. (Маслова; 1985)

Мыслительный процесс во фразеологических оборотах представлен как нечто овеществленное и полное таинственности, загадочности. Все очень просто и конкретно, например, sich den Kopf verkeilen (забивать себе голову ненужными вещами), ein Gedanke fährt (geht, läuft) j-m durch den Kopf (у кого-либо мелькает мысль), еtwas aus dem Kopf schlagen (выбросить что-то из головы) и др. Вместе с тем мыслительная деятельность представлена как активный процесс (используются глаголы, употребляющиеся с именами одушевленными), как процесс управляемый, зависящий от воли человека.

Волевой момент объединяет целую группу ФЕ: auf seinem Kopf bestehen (beharren) (упорствовать, стоять на своем), seinen Kopf aufsetzen (настоять на своем, добиться своего), seinen Kopf durchsetzen (пробиться в жизни), seinen Kopf für sich haben (быть упрямым, своевольным, себе на уме) и т.д.

Фразеология по-своему раскрывает познавательные процессы личности. Восприятие отражает в основном сема Zentrum der Sinnesorgane. Понятия о памяти, мышлении и воображении можно объяснить на основе семы Sitz des Gehirns. Так, переводным эквивалентом к слову Kорf в оборотах aus dem Kopfe wissen (spielen, aussagen) (знать, играть, говорить наизусть, по памяти), etwas im Kopfe behalten (сохранять в памяти, помнить, не забывать), etwas noch frisch im Kopf haben (хорошо помнить что-то) может служить русское «память». 
Своеобразно интерпретируется во фразеологии эмоционально-чувственная сторона деятельности личности. Иногда тематика ФЕ с элементом Корf отражает эмоции, связанные с самим мыслительным процессом, например, mir brummt der Kopf (у меня трещит голова от мыслей), viel im Kopf haben (много думать о чем-то), еіnеn heißen Kopf bekommen (запариться, получить трудную задачу), einen kühlen (klaren) Kopf bewahren (behalten) (coхранять спокойствие, хладнокровие), mein armer Kopf (я сойду с ума) (и т.д., и не имеющие к нему непосредственного отношения, например, j-m den Kopf heißmachen (заморочить, задать жару, взволновать), j-m den Корf verdrehen (вскружить голову), den Kopf verlieren (потерять самообладание, голову) и т.д.

Самую большую группу из фразеологизмов с компонентом значения Sitz des Gehirns представляют единицы качественно-оценочной характеристики, служащие для выражения отношения говорящего к умственным способностям других индивидов.

Для положительной характеристики часто достаточно подчеркнуть, что у человека есть голова, например, ein Mann von Kopf (человек с умом, умный человек); Kopf (Köpfchen) haben (быть толковым, смекалистым, умничкой); Köpfchen, Köpfchen! (Думать надо!) Иногда сочетание усиливается прилагательным положительной качественной характеристики: einen hellen (fixen, klaren, offenen) Kopf haben (иметь голову на плечах; быть расторопным малым; хорошо соображать).

По линии отрицательной характеристики интеллектуальных свойств человека можно выделить два типа: «патологические отклонения в психической деятельности» и «тупость, ограниченность, глупость». Во фразеологии границы между этими оттенками расплывчаты. Очень часто для усиления эффекта высказывания используются выражения с оттенком «ненормальный, помешанный» для оценки необдуманных действий.

Сема Zentrum der Sinnesorgane находит выражение в относительно небольшом числе фразеологизмов. Функции каждого органа чувств очевидны, и поэтому фразеология «предпочитает» название определенных органов чувств применительно к определенной ситуации.

Как центр ориентации в мире выступает слово Kopf, например, в ФЕ j-n mit dem Kopf auf etwas stoßen (ткнуть кого-то носом); в качестве сосредоточения органов чувств, например, в ФЕ einen roten Kopf bekommen (сильно покраснеть, как помидор, побагроветь) - причем Корf может означать не только лицо, но и любой орган, относящийся к нему: переводным эквивалентом к слову Корf в выражении den Kopf zumachen (заткнуться, замолчать) можно назвать лишь Mund (рот); для передачи особенной чувствительности развивается значение «самое чувствительное, самое ранимое, самое слабое место», например, чтобы подчеркнуть всю степень обиды, оскорбления: j-m etwas an den Kopf werfen, wie vor den Kopf geschlagen sein - русский эквивалент «бросить в лицо», «плюнуть в лицо» и т.д.

\section{Заключение}

Проведенное исследование показало, что все УСК с компонентом Корf соотносимы по своей семантике с определенной семой слова Кopf, взятого в прямом номинативном значении.

Статус УСК как сочетания слов способствует актуализации определенного оттенка значения слова Корf, высвечивает исходную сему развития значения, открывает возможности для интерпретации ФЕ. Все это, а также ситуативно-зашифрованная направленность номинации УСК позволяют актуализировать потенции слова-компонента УСК за счет внутреннего контекста УСК.

Нам кажется, что, несмотря на все вышесказанное, было бы неправомерно противопоставлять компоненты ФЕ слову, т.к. в сознании носителей языка слово останется словом, независимо от того, участвует ли оно в составе ФЕ или входит в свободное словосочетание. Кстати, в свободном словосочетании тоже реализуются не все потенции слова, а какой-либо из его лексико-семантических вариантов (Маслова, Гутарова, 2011), что в перспективе может стать основой дальнейшего исследования. В пользу этого говорит также семантическая вычленимость слов даже в ФЕ-некротизмах.

Особенность семантики компонентов УСК состоит в их двунаправленности: одновременной корреляции значения слова во всей его «глобальности» в сознании носителей языка и реализуемых за счет внутреннего контекста УСК потенций слова, когда на передний план выдвигаются зачастую не основные и даже не дифференцирующие, а потенциальные семы, малосущественные с точки зрения отражения объективных свойств предметов и явлений действительности, а подчас и основанные исключительно на логико-ассоциативных представлениях «народной психологии», но столь существенные для формирования значения УСК. Фразеологизм «обновляет» семантику слова, заставляет его заиграть новыми, часто неожиданными гранями, реализует семантические потенции слова, заложенные в нем как в единице языка (Гутарова, 2008). А слово в составе УСК - это частый случай применения слова. И в фразеологическом составе языка не может закрепиться ни одного УСК, в котором слово означало бы нечто такое, чего не позволяла бы семантическая система языка, в частности семантическая структура слов-компонентов. Наглядным подтверждением этого может служить семантика УСК с компонентом Корf, запрограммированным уже в самом значении данного слова.

\section{Источники | References}

1. Архангельский В. Л. Устойчивые фразы в современном русском языке. Ростов-на-Дону, 1964.

2. Бинович Л. Э., Гришин Н. Н. Немецко-русский фразеологический словарь. М., 1995. 
3. Богуславская И. В. Предикатные конструкции с дистантным расположением компонентов: автореф. дисс. ... к. филол. н. СПб., 1997.

4. Гутарова А. В. Аналитические глагольно-именные конструкции немецкого языка и их русские соответствия: автореф. дисс. ... к. филол. н. Казань, 2008.

5. Лепинг Е. И., Страхова Н. П., Филичева Н. И. и др. Большой немецко-русский словарь. М., 2017.

6. Маслова Н. А. Семантика и синтаксис производных имен существительных в современном немецком языке. Казань: КГУ, 1985.

7. Маслова Н. А., Гутарова А. В. Аналитизм глагольно-именных конструкций в немецком и русском языках. Казань: Отечество, 2011.

8. Мордвилко А. П. Очерки по русской фразеологии (именные и глагольные фразеологические обороты). М.: Просвещение, 1964.

9. Никитевич В. М. Основы номинативной деривации. М.: Высшая школа, 1985.

10. Пешковский А. М. Русский синтаксис в научном освещении. М.: Просвещение, 1956.

11. Чернышева И. И. Фразеологическая система и ее семантические категории // Иностранные языки в школе. М.: Высшая школа, 1973.

12. Brockhaus F. A., Wahrig G. Deutsches Wörterbuch: in 6 Bänden. Stuttgart, 1984.

13. Daniels K. Substantivierungstendenzen in der deutschen Gegenwartssprache - Nominaler Ausbau des verbalen Denkkreises. Düsseldorf, 1963.

14. Klappenbach R., Steinitz W. Wörterbuch der deutschen Gegenwartsprache. Berlin, 1994.

15. Lötzsch R. Deutsch-russisches Wörterbuch. Berlin, 1984.

16. Paul H. Deutsches Wörterbuch. Halle/Saale, 2011.

\section{Информация об авторах | Author information}

RU Гутарова Александра Викторовна ${ }^{1}$, к. филол. н.

${ }^{1}$ Казанский инновационный университет имени В. Г. Тимирясова (ИЭУП)

EN Gutarova Aleksandra Viktorovna ${ }^{1}, \mathrm{PhD}$

${ }^{1}$ Kazan Innovative University named after V. G. Timiryasov (IEML)

1g-a@inbox.ru

\section{Информация о статье | About this article}

Дата поступления рукописи (received): 07.11.2021; опубликовано (published): 28.12.2021.

Ключевые слова (keywords): фразеологическая единица; десемантизация; двунаправленность; семантическая близость; семантическая структура; phraseological unit; desemantisation; bidirectionality; semantic similarity; semantic structure. 